\title{
An update on the role of Atopobium vaginae in bacterial vaginosis: what to consider when choosing a treatment? A mini review
}

\author{
Werner Mendling $^{1}$ (D) Ana Palmeira-de-Oliveira ${ }^{2,3} \cdot$ Stephan Biber $^{4} \cdot$ Valdas Prasauskas $^{4}$
}

Received: 23 January 2019 / Accepted: 26 March 2019 / Published online: 5 April 2019

(c) The Author(s) 2019

\begin{abstract}
Introduction Bacterial vaginosis (BV) is the most common vaginal disorder in reproductive-age women. The condition is characterised by the replacement of a healthy, lactobacilli-dominated vaginal microbiota by anaerobic and facultative anaerobic bacteria. BV increases the risk of acquisition of STIs and is associated with pregnancy complications. Although the composition of the bacteria in BV varies between individuals, there are some species such as Gardnerella, Atopobium, Mycoplasma, Snethia, Megasphera, Dialister, etc., that are found most frequently.

Material and Methods Literature research to the importance of Atopobium vaginae in BV and treatment options.

Results Atopobium (A.) vaginae is an important component of the complex abnormal vaginal flora in BV; even though $A$. vaginae, like Gardnerella vaginalis, has also been detected in the normal flora, it is much more common in BV patients. A. vaginae has been shown to play an important role in the pathophysiology of $\mathrm{BV}$ and is thought to be at least a partial cause of the known negative sequelae. The presence of $A$. vaginae in the BV-associated biofilms and its resistance to some antimicrobial substances has been described - this seems to have a major impact on treatment outcome.

Conclusion Current scientific data demonstrate that dequalinium chloride (Fluomycin ${ }^{\circledR}$ ) is one of the valid therapeutic options for BV treatment, since it displays a broad antimicrobial spectrum against relevant vaginal pathogens, especially against $G$. vaginalis and A. vaginae, without having safety concerns.
\end{abstract}

Keywords Bacterial vaginosis $\cdot$ Bacterial biofilm $\cdot$ Atopobium vaginae $\cdot$ Metronidazole $\cdot$ Clindamycin $\cdot$ Dequalinium chloride $\cdot$ Microbial resistance

\section{Introduction}

Bacterial vaginosis (BV) is the most common vaginal disorder in reproductive-age women [1]. The condition is characterised by the replacement of a lactobacilli-dominated vaginal microbiota by anaerobic and facultative anaerobic bacteria. It is still unknown whether the loss of lactobacilli precedes or follows the upheaval of flora in BV [2].

Werner Mendling

w.mendling@t-online.de

1 German Center for Infections in Obstetrics and Gynaecology, Wuppertal, Germany

2 Labfit-HPRD: Health Products Research and Development, Lda, Covilhã, Portugal

3 CICS-UBI: Health Sciences Research Centre, University of Beira Interior, Covilhã, Portugal

4 Scientific and Medical Department, Medinova AG, Zurich, Switzerland
However, it seems to be quite certain that it is a preferential proliferation of the BV-related bacteria, rather than an exogenous acquisition [2].

Only some women with BV have symptoms, displaying a malodorous, watery, grey discharge. Because of the absence of inflammation, BV is not called vaginitis-there is no pain, no itching, no dyspareunia, no redness of the vulva or vagina, and no toxic leucocytes-only a microbial shift to anaerobic pathogens [3]. However, BV increases the risk of acquisition and transmission of STIs [4] and is associated with adverse obstetric and gynaecologic outcomes including miscarriage, premature labour, preterm birth, preterm prelabour rupture of membranes, chorioamnionitis, intrauterine infection, post-caesarean endometritis, upper genital tract infections, and pelvic inflammatory disease $[5,6]$.

Although the composition of the bacteria in BV varies between individuals, Gardnerella, Atopobium, Mycoplasma, Prevotella, Bifidobacterium, Megasphaera, Leptotrichia, Sneathia, Dialister, Clostridium, and Bacterial 
Vaginosis-Associated Bacterium (BVAB)-1, -2 and -3 species are found most frequently [7,8]. The association of $G$. vaginalis with BV was originally described by Gardner and Dukes already in 1955 [9]. G. vaginalis and Prevotella spp. are found in the disturbed vaginal microbiome, but they are also present in lower loads in healthy women [7, 10]. However, the involvement of A. vaginae in BV, although it rarely occurs in the absence of $G$. vaginalis, has only been established in recent years [11-13]. Increasing evidence on its involvement in BV biofilm formation, as well as on specific resistances of $A$. vaginae against standard antibiotics may explain therapeutic failures and recurrences of BV [14].

Despite the current knowledge on BV many questions regarding treatment remain unanswered-all current therapies have disadvantages and gaps [14]. This mini review describes the current scientific knowledge regarding the relevance of $A$. vaginae in the pathogenesis of $\mathrm{BV}$ and what should be considered when choosing a treatment.

\section{Role of A. vaginae in BV}

Atopobium vaginae is a newly discovered bacterium frequently found in women with BV [15]. The name Atopobium, meaning "strange living thing" in Greek, was proposed in 1992 [16] to reclassify three bacterial species formerly designated Lactobacillus minutus, Lactobacillus rimae and Streptococcus parvulus. Genus Atopobium belongs to the Coriobacteriaceae family and A. minutum, A. rimae, A. parvulum, and, later described $A$. deltae and $A$. fossor, can be distinguished [15]. In 1999 Rodriguez et al. [17] first described A. vaginae isolated from the vagina of a healthy women in Sweden. These are Gram-positive, elliptical or rod-shaped cocci, nonmotile and non-spore-forming organisms, and occur alone, in pairs, in clumps or in short chains (Fig. 1). They produce major amounts of lactic acid next to acetic and formic acids and are strictly anaerobic.

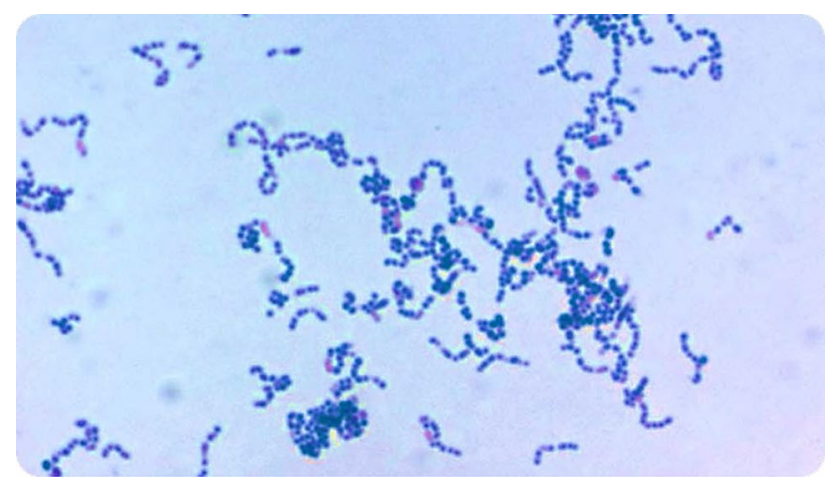

Fig. 1 Atopobium vaginae culture, Gram stain, magnification $100 \times$ (courtesy of M. Vaneechoutte, Belgium)
Only recently, the association of $A$. vaginae with BV was reported $[11,12]$ and many subsequent studies have confirmed the bacterium to be an important component of the complex abnormal vaginal flora in BV [11, 12, 18-21]. Even though A. vaginae, as $G$. vaginalis, has also been detected in the normal vaginal flora (8\% [11] up to $25 \%$ [19]), it is found much more commonly in BV patients (50\% [12], 55\% [11], 83\% [18], 96\% [19]). Also, the differences between African and Caucasian women, referring the prevalence of $A$. vaginae in the first ones have been described [22]. Loads of $G$. vaginalis, A. vaginae, and other typical $\mathrm{BV}$-pathogens are significantly higher in the BV-positive group than in healthy controls [23]. Additionally, A. vaginae has been positively associated with $\mathrm{BV}$ typical vaginal discharge, an elevated $\mathrm{pH}$ and the presence of clue cells $[18,24]$. It was also described that high vaginal loads of $A$. vaginae in combination with G. vaginalis are associated with late miscarriage and prematurity [6, 25]. Additionally, it was demonstrated using an in vitro model that $A$. vaginae stimulates an innate immune response from epithelial cells, leading to localised IL-6 and IL-8 and an antimicrobial $\beta$-defensin peptide production occurring after triggering the toll-like receptor 2 , and this possibly contributes to the pathogenesis of BV [26]. Hence, in BV G. vaginalis and A. vaginae still belong to 'the main suspects', a possible synergism between the two organisms has been considered, and because of this several authors using molecular-based techniques have examined the possibility of combining loads of A. vaginae and G. vaginalis as a means of diagnosing BV [15, 27, 28].

\section{Involvement of $A$. vaginae in biofilm formation}

Bacteria rarely exist as single-species planktonic forms but thrive in complex polymicrobial adhering communities enveloped by extracellular matrices, so-called biofilms. The bacteria account for less than $10 \%$ of biofilm mass, whereas the biofilm matrix usually accounts for more than $90 \%$ and provides the best living conditions for the bacteria [29]. Costerton et al. in 1999 [30] have described the association of a bacterial biofilm with various chronic infections. Regardless of the location in the human body, biofilm infections share similar clinical characteristics. They grow slowly, and bacterial communities are rarely fully destroyed by the hostdefence mechanisms. Bacteria in biofilm release antigens resulting in an increase in antibody production. However, due to the biofilm structure, the produced antibodies are not capable of killing the biofilm bacteria [30].

The biofilm formation in $\mathrm{BV}$ is a virulence mechanism that enhances pathogenicity [31]. The polymicrobial BVbiofilm can be seen with the Gram-stain method in the form of clue cells, which are vaginal epithelial cells covered by 
layers of adherent Gram-negative and/or -variable cells. Using fluorescence in situ hybridisation (FISH) method, the structure and composition of the biofilm can be studied in more detail [32], especially considering the combined presence of G. vaginalis and A. vaginae. Hardy et al. [33], similar to that previously described by Swidsinski et al. [31], have demonstrated that adherent $A$. vaginae and $G$. vaginalis were visualised in, respectively, $54 \%$ and $82 \%$ of samples with bacterial biofilm in BV. It was detected that $G$. vaginalis accounted for $60 \%$ or more and A. vaginae accounted for $40 \%$ or less of the film bacterial composition. It is assumed that $G$. vaginalis acts as an initial coloniser to establish early biofilm structures to which secondary colonisers, such as A. vaginae can attach $[33,34]$. The fact that $G$. vaginalis is capable of displacing protective lactobacilli on pre-coated vaginal epithelial cells, is probably related to its ability to promote biofilm formation. In contrast, the other anaerobes, including $A$. vaginae, are easily outcompeted by $L$. crispatus [35]. Hardy et al. [33] also demonstrated the important role of $A$. vaginae together with $G$. vaginalis in $\mathrm{BV}$-associated biofilm. Interactions among these species within a biofilm are synergistic: these include co-aggregation, metabolic cooperation and increased resistance to antibiotics or host immune responses and have important clinical implications [36]. The presence of a biofilm-due to increased resistance to treatment-is thought to be one of the possible reasons for the $\mathrm{BV}$ recurrence $[37,38]$.

\section{Considerations on conventional treatments}

Concerning the treatment options, the mainstay of BV treatment in many countries remains either oral or vaginal metronidazole once a day for 5-7 days or vaginal clindamycin as first-line treatments. The efficacy of the treatment with metronidazole is comparable to topical clindamycin [39]. Cure rates, following intravaginal treatment with metronidazole or clindamycin, account for $70-90 \%$ at the end of treatment and 1 month after the end of therapy [3, 4, 40]. However, as it was first and best described by Larsson and Forsum in 2005 [39], 3 months after the treatment the recurrence rate can exceed 30\% [41].

De Backer et al. [42] demonstrated that susceptibility to metronidazole varied significantly across various $A$. vaginae strains in vitro. Some of the investigated clinical isolates of A. vaginae were shown to be highly resistant to nitroimidazoles such as metronidazole and secnidazole $[11,43]$ and it was suggested that this could play a role in treatment failure $[11,42]$. Susceptibility testing for metronidazole of additional A. vaginae isolates demonstrated that the minimum inhibition concentration (MIC) is variable, ranging from $2 \mu \mathrm{g} / \mathrm{mL}$ (sensitive) to more than $256 \mu \mathrm{g} / \mathrm{mL}$ (resistant) [12]. So far more than half of the tested isolates were resistant.

Beigi and colleagues described a significant increase of clindamycin-resistant anaerobic bacteria after treatment [44]. It is unclear if this is true for A. vaginae specifically. Even though these resistance findings seem to be interesting, it is questionable whether it influences clinical efficacy in patients with recurrent BV formerly treated with clindamycin. In vitro data suggest that clindamycin is effective against A. vaginae already at low concentrations [45].

\section{Exploring alternative approaches}

Alternatives to current antibiotic treatments against BV are increasingly being explored: antiseptics, probiotics, plant-derived compounds, vaginal acidifying and buffering agents, as well as different combination therapies are increasingly used [46-48]. A big interest, due to beneficial
Fig. 2 Mode of action of dequalinium chloride [47]. Dequalinium chloride (DQC) acts as a microbicidal against all main vaginal pathogens and due to the multiple modes of action, the development of resistances is unlikely

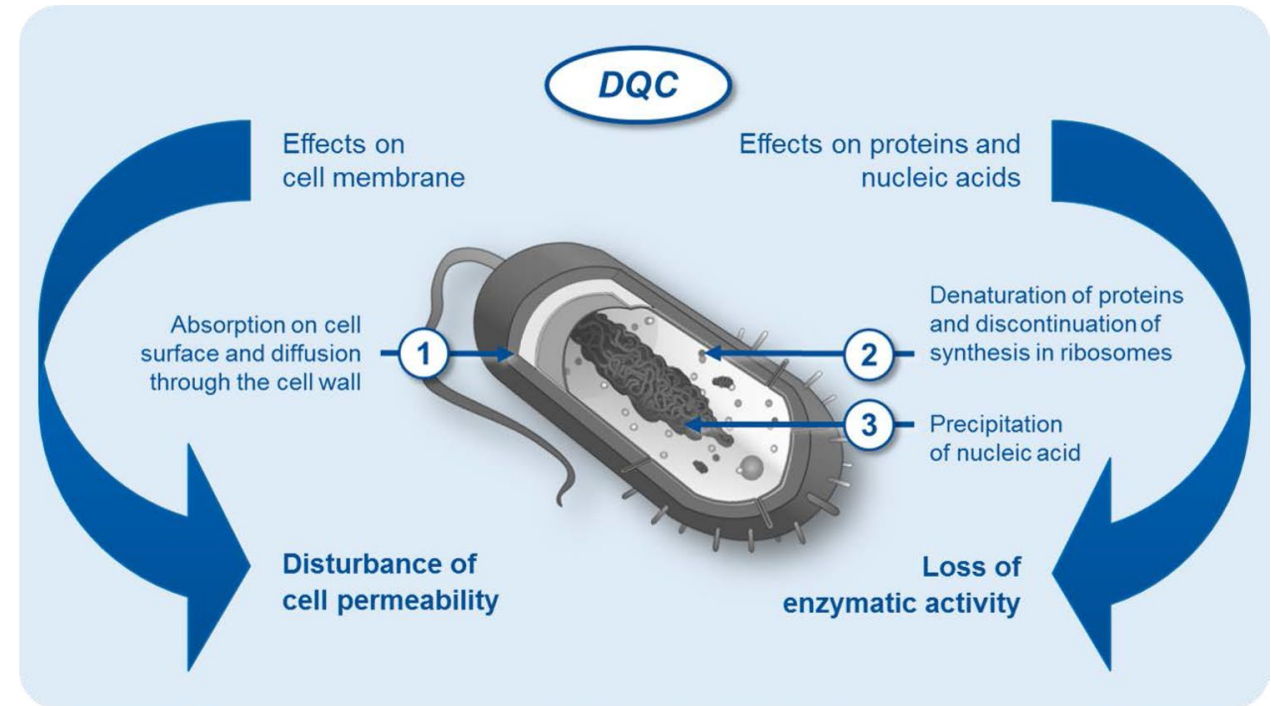


BV

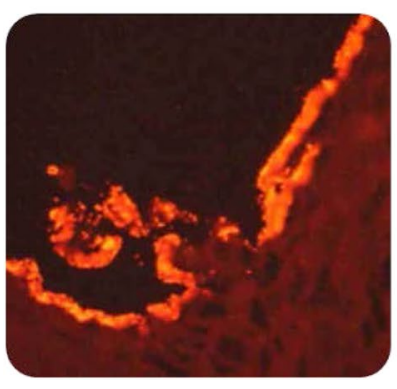

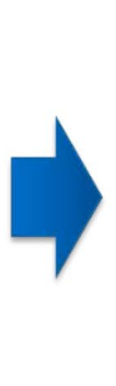

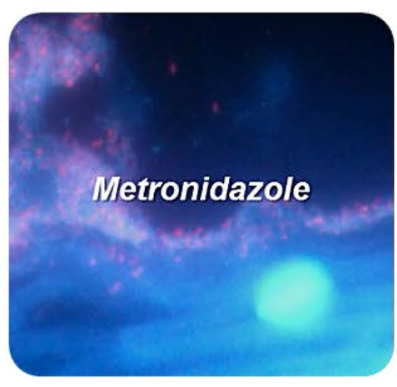

Asymptomatic

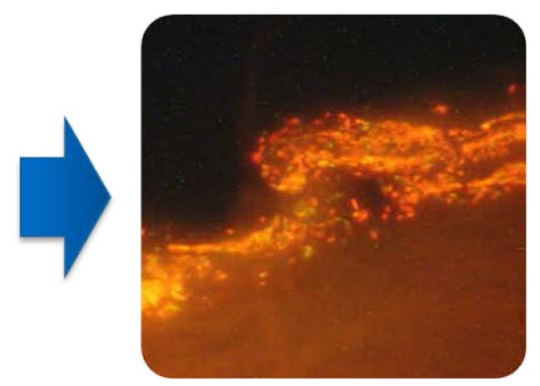

Fig. 3 BV-biofilm [31, 38]. A bacterial biofilm, an adhering microbial community enveloped by extracellular matrices, is considered one of the possible reasons for the BV recurrence

characteristics, has been seen in a group of antimicrobial substances belonging to antiseptics, such as dequalinium chloride (DQC) (Fig. 2) [47]. DQC was recently listed in an international guideline as an alternative treatment for BV [49]. Some authors [50] have suggested that DQC, as an antiseptic substance, could be preferable to a repeated course of antibiotics for patients with frequently recurrent BV. The antimicrobial activity of DQC has been investigated and demonstrated over the past decades by several investigators [51-55]. Della Casa et al. [51] has demonstrated the in vitro antimicrobial activity of this substance against different pathogens that are relevant for vaginal infections, including anaerobic bacteria ( $G$. vaginalis, etc.), aerobic bacteria (staphylococci, streptococci, etc.), and Candida species. Additionally, the non-inferiority of DQC vaginal tablets to clindamycin vaginal cream for the treatment of BV has been demonstrated in a clinical study by Weissenbacher et al. [48]. Based on Amsel's criteria, the clinical cure rates 4 weeks after the end of treatment with DQC were $79.5 \%$ and $77.6 \%$ with clindamycin, respectively.

It has been shown that a high concentration of $A$. vaginae before treatment was associated with complete or partial failure of treatment for BV [11, 42]. Additionally, the presence of A. vaginae in the $\mathrm{BV}$-associated biofilm has been described [31] and it seems that this knowledge has a major impact on treatment [33].

A recent study by Lopes dos Santos Santiago et al. [45] has investigated the in vitro susceptibility of $A$. vaginae to DQC in comparison to established substances (metronidazole and clindamycin). The MIC (minimal inhibition concentration) and MBC (minimal bactericidal concentration) range of DQC for 28 strains, belonging to 4 species of the genus Atopobium, i.e., A. minutum, A. rimae, A. parvulum, and $A$. vaginae, have been determined. The MIC and MBC for Atopobium spp. to DQC ranged between $<0.0625$ and $2 \mu \mathrm{g} / \mathrm{mL}$ with an $\mathrm{MIC}_{90}$-value of $2 \mu \mathrm{g} / \mathrm{mL}$. The $\mathrm{MIC}_{90}$-value for $A$. vaginae was demonstrated to be $0.5 \mu \mathrm{g} / \mathrm{mL}$, i.e., $A$. vaginae was more sensitive than the other species tested. Not only was growth of A. vaginae inhibited at the MIC-levels, but the bacterial cells were also killed. The MICs of clindamycin and DQC for A. vaginae in this study were similar (sensitive), whereas the MIC of metronidazole was much higher (resistant) [45].

\section{Biofilm disruption for treatment success}

Persistence of an adherent bacterial biofilm, containing mostly G. vaginalis and A. vaginae, can be considered as the major reason for failure of BV treatment (Fig. 3) [31, 38]. Bacteria in biofilms are less susceptible to antibiotics compared to planktonic cells and have a higher tolerance towards antimicrobial treatment [56]. It was found, that although all patients recovered after oral metronidazole treatment, a large reservoir of A. vaginae (together with $G$. vaginalis) was persisting as a bacterial biofilm [38]. Additionally, an in vivo study with topical metronidazole gel by Bradshaw et al. [57] found that rates of recurrence of BV were higher when A. vaginae was present in addition to G. vaginalis. Interestingly, an in vitro study has demonstrated the ability of beneficial Lactobacillus spp. to disrupt the biofilm consisting of A. vaginae and G. vaginalis [58].

In the course of recent in vitro investigations, Gottschick and colleagues have screened various compounds for vaginal Biofilms (consisting of G. vaginalis): tThe antibiotics, such as metronidazole and tobramycin were effective in preventing biofilm formation, but had no effect on an established biofilm, while some antiseptic substances led to the disintegration of existing biofilms [59]. Recent not yet published in vitro data are suggesting that DQC could be effective in disrupting the BV-biofilm under experimental conditions [60].

\section{Conclusions}

A. vaginae is an important component of the complex abnormal vaginal flora in BV. Resistance of A. vaginae to metronidazole, one of the current first-line treatments, as well 
as the presence of A. vaginae in the $\mathrm{BV}$-associated biofilm have been described. Although more clinical data would be needed on this subject, this seems to have a major impact on BV treatment outcomes. Nevertheless, recently available scientific data confirms that DQC (Fluomizin ${ }^{\circledR}$ ) is one of the valid therapeutic options for BV treatment, as it displays a broad antimicrobial spectrum against relevant vaginal pathogens, especially against $G$. vaginalis and A. vaginae, without having safety concerns.

Acknowledgements The authors would like to thank Gabriela Zwyssig and Dr Philipp Grob, Medinova AG, Switzerland for their comments on the manuscript.

Author contributions The author WM received a honorary for the manuscript. All authors contributed to the manuscript.

Funding This review and online free access of the publication was sponsored by Medinova AG, Switzerland.

\section{Compliance with ethical standards}

Conflict of interest Dr Valdas Prasauskas and Stephan Biber are employees of Medinova AG, Switzerland.

Open Access This article is distributed under the terms of the Creative Commons Attribution 4.0 International License (http://creativeco mmons.org/licenses/by/4.0/), which permits unrestricted use, distribution, and reproduction in any medium, provided you give appropriate credit to the original author(s) and the source, provide a link to the Creative Commons license, and indicate if changes were made.

\section{References}

1. Kenyon C, Colebunders R, Crucitti T (2013) The global epidemiology of bacterial vaginosis: a systematic review. Am J Obstet Gynecol

2. Srinivasan S, Fredricks DN (2008) The human vaginal bacterial biota and bacterial vaginosis. Interdiscip Perspect Infect Dis 2008:750479

3. Donders G (2010) Diagnosis and management of bacterial vaginosis and other types of abnormal vaginal bacterial flora: a review. Obstet Gynecol Surv 65:462-473

4. Nasioudis D, Linhares IM, Ledger WJ, Witkin SS (2017) Bacterial vaginosis: a critical analysis of current knowledge. BJOG 124:61-69

5. Witkin $\mathrm{S}$ (2014) The vaginal microbiome, vaginal anti-microbial defence mechanisms and the clinical challenge of reducing infection-related preterm birth. BJOG

6. Menard JP, Mazouni C, Salem-Cherif I, Fenollar F, Raoult D, Boubli L, Gamerre M, Bretelle F (2010) High vaginal concentrations of Atopobium vaginae and Gardnerella vaginalis in women undergoing preterm labor. Obstet Gynecol 115:134-140

7. Srinivasan S, Hoffman NG, Morgan MT, Matsen FA, Fiedler TL, Hall RW, Ross FJ, McCoy CO, Bumgarner R, Marrazzo JM, Fredricks DN (2012) Bacterial communities in women with bacterial vaginosis: high resolution phylogenetic analyses reveal relationships of microbiota to clinical criteria. PLoS ONE 7:e37818
8. Cox C, Watt AP, McKenna JP, Coyle PV (2016) Mycoplasma hominis and Gardnerella vaginalis display a significant synergistic relationship in bacterial vaginosis. Eur J Clin Microbiol Infect Dis 35:481-487

9. Gardner HL, Dukes CD (1955) Haemophilus vaginalis vaginitis: a newly defined specific infection previously classified "nonspecific" vaginitis. Am J Obstet Gynecol 69:962-976

10. Fredricks DN, Fiedler TL, Thomas KK, Oakley BB, Marrazzo JM (2007) Targeted PCR for detection of vaginal bacteria associated with bacterial vaginosis. J Clin Microbiol 45:3270-3276

11. Ferris MJ, Masztal A, Aldridge KE, Fortenberry JD, Fidel PL Jr, Martin DH (2004) Association of Atopobium vaginae, a recently described metronidazole resistant anaerobe, with bacterial vaginosis. BMC Infect Dis 4:5

12. Burton JP, Devillard E, Cadieux PA, Hammond JA, Reid G (2004) Detection of Atopobium vaginae in postmenopausal women by cultivation-independent methods warrants further investigation. J Clin Microbiol 42:1829-1831

13. Verstraelen H, Verhelst R, Claeys G, Temmerman M, Vaneechoutte M (2004) Culture-independent analysis of vaginal microflora: the unrecognized association of Atopobium vaginae with bacterial vaginosis. Am J Obstet Gynecol 191:1130-1132

14. Donders GG, Zodzika J, Rezeberga D (2014) Treatment of bacterial vaginosis: what we have and what we miss. Expert Opin Pharmacother 15:645-657

15. Lamont R, Sobel J, Akins R, Hassan S, Chaiworapongsa T, Kusanovic J, Romero R (2011) The vaginal microbiome: new information about genital tract flora using molecular based techniques. BJOG 118:533-549

16. Collins MD, Wallbanks S (1992) Comparative sequence analyses of the 16S rRNA genes of Lactobacillus minutus, Lactobacillus rimae and Streptococcus parvulus: proposal for the creation of a new genus Atopobium. FEMS Microbiol Lett 74:235-240

17. Rodriguez Jovita M, Collins MD, Sjoden B, Falsen E (1999) Characterization of a novel Atopobium isolate from the human vagina: description of Atopobium vaginae sp. nov. Int J Syst Bacteriol 49(Pt 4):1573-1576

18. De Backer E, Verhelst R, Verstraelen H, Alqumber MA, Burton JP, Tagg JR, Temmerman M, Vaneechoutte M (2007) Quantitative determination by real-time PCR of four vaginal Lactobacillus species, Gardnerella vaginalis and Atopobium vaginae indicates an inverse relationship between L. gasseri and L. iners. BMC Microbiol 7:115

19. Fredricks DN, Fiedler TL, Marrazzo JM (2005) Molecular identification of bacteria associated with bacterial vaginosis. N Engl J Med 353:1899-1911

20. Marconi C, Cruciani F, Vitali B, Donders GG (2012) Correlation of Atopobium vaginae amount with bacterial vaginosis markers. J Low Genit Tract Dis 16:127-132

21. Verhelst R, Verstraelen H, Claeys G, Verschraegen G, Delanghe J, Van Simaey L, De Ganck C, Temmerman M, Vaneechoutte M (2004) Cloning of 16S rRNA genes amplified from normal and disturbed vaginal microflora suggests a strong association between Atopobium vaginae, Gardnerella vaginalis and bacterial vaginosis. BMC Microbiol 4:16

22. Zhou X, Brown CJ, Abdo Z, Davis CC, Hansmann MA, Joyce P, Foster JA, Forney LJ (2007) Differences in the composition of vaginal microbial communities found in healthy Caucasian and black women. ISME J 1:121-133

23. Wang KD, Su JR (2014) Quantification of Atopobium vaginae loads may be a new method for the diagnosis of bacterial vaginosis. Clin Lab 60:1501-1508

24. Silva D, Henriques A, Cereija T, Martinez-de-Oliveira J, Miranda M, Cerca N (2014) Prevalence of Gardnerella vaginalis and Atopobium vaginae in Portuguese women and association 
with risk factors for bacterial vaginosis. Int J Gynaecol Obstet 124:178-179

25. Bretelle F, Rozenberg P, Pascal A, Favre R, Bohec C, Loundou A, Senat MV, Aissi G, Lesavre N, Brunet J et al (2015) High Atopobium vaginae and Gardnerella vaginalis vaginal loads are associated with preterm birth. Clin Infect Dis 60:860-867

26. Libby EK, Pascal KE, Mordechai E, Adelson ME, Trama JP (2008) Atopobium vaginae triggers an innate immune response in an in vitro model of bacterial vaginosis. Microbes Infect 10:439-446

27. Menard JP, Fenollar F, Henry M, Bretelle F, Raoult D (2008) Molecular quantification of Gardnerella vaginalis and Atopobium vaginae loads to predict bacterial vaginosis. Clin Infect Dis 47:33-43

28. Henriques A, Cereija T, Machado A, Cerca N (2012) In silico vs in vitro analysis of primer specificity for the detection of Gardnerella vaginalis, Atopobium vaginae and Lactobacillus spp. BMC Res Notes 5:637

29. Flemming HC, Wingender J (2010) The biofilm matrix. Nat Rev Microbiol 8:623-633

30. Costerton JW, Stewart PS, Greenberg EP (1999) Bacterial biofilms: a common cause of persistent infections. Science 284:1318-1322

31. Swidsinski A, Mendling W, Loening-Baucke V, Ladhoff A, Swidsinski S, Hale LP, Lochs H (2005) Adherent biofilms in bacterial vaginosis. Obstet Gynecol 106:1013-1023

32. Hardy L, Jespers V, Dahchour N, Mwambarangwe L, Musengamana V, Vaneechoutte M, Crucitti T (2015) Unravelling the bacterial vaginosis-associated biofilm: a multiplex Gardnerella vaginalis and Atopobium vaginae fluorescence in situ hybridization assay using peptide nucleic acid probes. PLoS ONE 10:e0136658

33. Hardy L, Jespers V, Abdellati S, De Baetselier I, Mwambarangwe L, Musengamana V, van de Wijgert J, Vaneechoutte M, Crucitti T (2016) A fruitful alliance: the synergy between Atopobium vaginae and Gardnerella vaginalis in bacterial vaginosis-associated biofilm. Sex Transm Infect

34. Machado A, Cerca N (2015) Influence of biofilm formation by Gardnerella vaginalis and other anaerobes on bacterial Vaginosis. $\mathrm{J}$ Infect Dis

35. Machado A, Salgueiro D, Harwich M, Jefferson KK, Cerca N (2013) Quantitative analysis of initial adhesion of bacterial vaginosis-associated anaerobes to ME-180 cells. Anaerobe 23:1-4

36. Elias S, Banin E (2012) Multi-species biofilms: living with friendly neighbors. FEMS Microbiol Rev 36:990-1004

37. Swidsinski A, Dorffel Y, Loening-Baucke V, Mendling W, Verstraelen H, Dieterle S, Schilling J (2010) Desquamated epithelial cells covered with a polymicrobial biofilm typical for bacterial vaginosis are present in randomly selected cryopreserved donor semen. FEMS Immunol Med Microbiol 59:399-404

38. Swidsinski A, Mendling W, Loening-Baucke V, Swidsinski S, Dorffel Y, Scholze J, Lochs H, Verstraelen H (2008) An adherent Gardnerella vaginalis biofilm persists on the vaginal epithelium after standard therapy with oral metronidazole. Am J Obstet Gynecol 198:96-97

39. Larsson PG, Forsum U (2005) Bacterial vaginosis-a disturbed bacterial flora and treatment enigma. APMIS 113:305-316

40. Livengood $\mathrm{CH}$ (2009) Bacterial vaginosis: an overview for 2009. Rev Obstet Gynecol 2:28-37

41. Bradshaw CS, Morton AN, Hocking J, Garland SM, Morris MB, Moss LM, Horvath LB, Kuzevska I, Fairley CK (2006) High recurrence rates of bacterial vaginosis over the course of 12 months after oral metronidazole therapy and factors associated with recurrence. J Infect Dis 193:1478-1486

42. De Backer E, Verhelst R, Verstraelen H, Claeys G, Verschraegen G, Temmerman M, Vaneechoutte M (2006) Antibiotic susceptibility of Atopobium vaginae. BMC Infect Dis 6:51
43. De Backer E, Dubreuil L, Brauman M, Acar J, Vaneechoutte M (2010) In vitro activity of secnidazole against Atopobium vagi$n a e$, an anaerobic pathogen involved in bacterial vaginosis. Clin Microbiol Infect 16:470-472

44. Beigi RH, Austin MN, Meyn LA, Krohn MA, Hillier SL (2004) Antimicrobial resistance associated with the treatment of bacterial vaginosis. Am J Obstet Gynecol 191:1124-1129

45. Lopes dos Santos Santiago G, Grob P, Verstraelen H, Waser F, Vaneechoutte M (2012) Susceptibility testing of Atopobium vaginae for dequalinium chloride. BMC Res Notes 5:151

46. Polatti F (2012) Bacterial vaginosis, Atopobium vaginae and nifuratel. Curr Clin Pharmacol 7:36-40

47. Mendling W, Weissenbacher ER, Gerber S, Prasauskas V, Grob $P$ (2016) Use of locally delivered dequalinium chloride in the treatment of vaginal infections: a review. Arch Gynecol Obstet 293:469-484

48. Weissenbacher ER, Donders G, Unzeitig V, de Martinez TB, Gerber S, Halaska M, Spacek J (2012) A comparison of dequalinium chloride vaginal tablets (Fluomizin(R)) and clindamycin vaginal cream in the treatment of bacterial vaginosis: a single-blind, randomized clinical trial of efficacy and safety. Gynecol Obstet Invest 73:8-15

49. Sherrard J, Wilson J, Donders G, Mendling W, Jensen JS (2018) European (IUSTI/WHO) International Union against sexually transmitted infections (IUSTI) World Health Organisation (WHO) guideline on the management of vaginal discharge. Int J STD AIDS 2018:956462418785451

50. Hay P (2017) Bacterial vaginosis. F1000Res 6:1761.

51. Della Casa V, Noll H, Gonser S, Grob P, Graf F, Pohlig G (2002) Antimicrobial activity of dequalinium chloride against leading germs of vaginal infections. Arzneimittelforschung 52:699-705

52. D'Auria FD, Simonetti G, Strippoli V (1989) Caratteristiche antimicrobiche di una tintura al dequalinio cloruro. Ann Ig $1: 1227-1241$

53. Cox WA (1965) Site of action of certain antibacterial heterocyclic quaternary ammonium compounds. Appl Microbiol 13:956-966

54. Babbs M, Collier HOJ, Austin WC, Potter MD, Taylor EP (1956) Salts of decamethylene-bis-4-aminoquinaldinium (Dequadin), a new antimicrobial agent. J Pharm Pharmacol 8:110-119

55. Cella JA, Eggenberger DN, Harriman LA, Harwood HJ (1952) The relation of structure and critical concentration to the bactericidal activity of quaternary ammonium salts. J Am Chem Soc 74:2061-2062

56. Anderl JN, Franklin MJ, Stewart PS (2000) Role of antibiotic penetration limitation in Klebsiella pneumoniae biofilm resistance to ampicillin and ciprofloxacin. Antimicrob Agents Chemother 44:1818-1824

57. Bradshaw CS, Tabrizi SN, Fairley CK, Morton AN, Rudland E, Garland SM (2006) The association of Atopobium vaginae and Gardnerella vaginalis with bacterial vaginosis and recurrence after oral metronidazole therapy. J Infect Dis 194:828-836

58. McMillan A, Dell M, Zellar MP, Cribby S, Martz S, Hong E, Fu J, Abbas A, Dang T, Miller W, Reid G (2011) Disruption of urogenital biofilms by lactobacilli. Colloids Surf B Biointerfaces 86:58-64

59. Gottschick C, Szafranski SP, Kunze B, Sztajer H, Masur C, Abels C, Wagner-Dobler I (2016) Screening of compounds against Gardnerella vaginalis biofilms. PLoS ONE 11:e0154086

60. Palmeira-de-Oliveira A, Personal communication, 2018.

Publisher's Note Springer Nature remains neutral with regard to jurisdictional claims in published maps and institutional affiliations. 